\title{
Experiences of Being Hospitalized in a Single Bedroom versus a Four Bedroom: An Interview Study
}

Brauner $\mathrm{AB}^{1^{*}}$, Jørgensen $\mathrm{L}^{2}$, Madsen $\mathrm{SB}^{2}$, Bernstein $\mathrm{I}^{2}$ and Petersen $\mathrm{HK}^{3}$

${ }^{1}$ Department of Surgery, Viborg Regional Hospital, Denmark

${ }^{2}$ Department of Surgery and Cancer, Aalborg University Hospital, Denmark

${ }^{3}$ Department of Surgery, Randers Regional Hospital, Denmark

*Corresponding author: Annette Boesen Brauner, Department of Surgery, Viborg Regional Hospital, Denmark,Tel: 4578440000, E-mail: annetteboesen@gmail.com Received date: August 5, 2017; Accepted date: August 18, 2017; Published date: August 25, 2017

Copyright: ( 2017 Brauner AB, et al. This is an open-access article distributed under the terms of the Creative Commons Attribution License, which permits unrestricted use, distribution, and reproduction in any medium, provided the original author and source are credited.

\begin{abstract}
Introduction: Great investments are made in new hospital buildings all in favour of single bedrooms for patients. Conclusions regarding the impact of single bedrooms versus multi bedrooms vary.
\end{abstract}

Method: We performed semi-structured interviews with patients undergoing surgery for rectal cancer about their preferences and experiences regarding hospitalization in a single bedroom or a multi bedroom. The data were collected during 2016.

Results: The company of fellow patients seems to be of great importance. Patients find the company healing and it contributed to feeling safer. Disturbances like sound and too much activity in a four bedroom is a problem. Most patients preferred single bedrooms when talking to visitors and when they felt very sick.

Conclusion: Many patients preferred four bedrooms over single bedrooms because of the company from fellow patients. This conflicts with the tendency in modern hospital design which favors all single bedrooms.

Keywords: Single bedroom; Four bedroom; Patient; Preference; Interview study; Health care design

\section{Introduction}

In these years great investments are made in hospital buildings and renovations all in favour of single bedrooms for patients [1]. Arguments for abolition of multi bedrooms are mainly based on the belief that patients prefer single bedrooms, but conclusions regarding the impact of single bedroom versus multi bedroom vary $[2,3]$.

\section{Background}

In 1984, a study showed that length of hospital stay and use of analgesics after cholecystectomy was decreased in patients with a nature view compared to patients with a view to a brick wall [4]. Since then, other studies have shown that there seems to be a connection between hospital interior design such as light, music, art on the walls etc and patients' perception of pain, anxiety and length of hospital stay [4-6]. Reviews about evidence based health care design conclude that single bedrooms decrease infection rate and promote healing and sleep quality [7-9] although conflicting results on infection rate reduction are found by others $[3,10]$.

In a single bedroom, patient integrity and privacy seems easier to withhold, but the surveillance of patients is often easier in a multi bedroom as the staff can monitor more patients at a time [11-13]. Patients enjoy the security of being visible to staff and to each other [10]. On the other hand, being cared for in a single bedroom means that patients can have a feeling of security, because they are able to create a personal environment without disruptive elements. This allows patients to focus on themselves and is thought to facilitate recovery [11]. Contrary, being admitted to a single bedroom imply feelings of loneliness and isolation, which can be frightening [11].According to Williams \& Gardiner, fellow patients can provide a feeling of safety and prevent the feeling of isolation, and this might even shorten length of hospital stay, but the positive interaction can be vulnerable if a patient becomes very sick or delirious $[11,14,15]$.

In single bedrooms patients get rest without disturbances, can have visitors without disturbing others but might be less encouraged mobilizing, if all they need is in the room. Another study showed that social interaction with other patients was not facilitated without effort and planning from the staff [16]. In single bedrooms the staffs is often the patient's main contact given that most patients stay in their room. According to Maben et al. patients rarely use dayrooms and therefore interactions with other patients are often absent in wards with only single bedrooms [10]. In conclusion, knowledge about patient's admission in a single bedroom versus a multi bedroom is insufficient and even contradictory. Therefore we decided to look futher in to this. The purpose of this interview study was to examine the preferences for, and experiences of single versus four edrooms in surgical patients with rectal cancer before admission and at discharge. 


\section{Material and Methods}

\section{Settings and participants}

The study was conducted in 2016 at the Department of Abdominal Surgery at Aalborg University Hospital. This department has 6 single bedrooms and 3 four bedrooms, and has room for 18 patients.

Data for this study consists of double semi-structured interviews with patients undergoing fast track surgery for rectal cancer. The inclusion criteria were patients who were willing to talk about their preferences and experiences regarding hospitalization in a single bedroom or a multi bedroom, Danish speaking and older than the age of 18. The participants were recruited consecutively either at their outpatient visit at which they were informed about their rectal cancer, or at the ward, when they were admitted to surgery. The interviews were based on a structured interview guide, but were also supposed to be flexible allowing the interviewer to respond to the participants for more detailed responses where appropriate. Patients were interviewed the day before surgery about their preferences regarding hospitalization in a single bedroom or a four bedroom, and again at discharge about their experiences of being hospitalized in either a single bedroom or a four bedroom. Patients were assigned to either single bedrooms or four bedrooms depending on occupancy on the ward. All interviews took place at the hospital.

\section{Analysis}

The data analysis was inspired by Steinar Kvales method of meaning condensation. First, all interviews were read to get a sense of the entirety. Second, the meaning units were stated as the participants expressed them. The third level was to derive themes based on the meaning units [17]. Data were analyzed by two of the authors (AB and $\mathrm{LJ}$ ) independently. Discrepancy was eliminated by discussion between $\mathrm{AB}$ and $\mathrm{LJ}$.

\section{Findings}

Twenty-one patients (16 men and 5 women) were interviewed before having surgery and at discharge. Fifteen patients were assigned to four bedrooms and 6 to single bedrooms. One patient was offered a single bedroom, but declined the offer as he wished to be admitted with a fellow patient, who he had met on the ward.

Based on the interviews the following themes emerged:

- Preferences for being hospitalized in a single bedroom versus a four bedroom and

- Pros and cons for being in a single bedroom versus a four bedroom

\section{Preferences for being hospitalized in a single bedroom versus a four bedroom}

Before admission, it seemed important to be hospitalized in a single bedroom, to be able to have visitors with nobody listening to the conversation "it was possible to talk to my two daughters, who were living far away and could not be here". Another reason for wanting a single bedroom was "the experience of being serious ill", which gave the possibility of privacy in a very vulnerable situation and being seriously ill could also mean many visitors, which then could disturb other patients. On the other hand, being alone could mean that very few people came to the room and "it could be quiet as in hell with nobody to talk to. However, in a single bedroom it is quiet, and you can "get visits without disturbing other people". Another patient supplemented that it was possible to "watch television without disturbing others". These quotations show that it seemed important to be thoughtful to other people and sometimes this can be difficult if you feel sick with eg vomiting after surgery. On the contrary, there is "nobody to have a community with and to share experiences of being ill with rectal cancer" or as expressed by another person who preferred to be hospitalized in a four bedroom "it is possible to get support and help from other patients and their relatives". Some patients preferred to be alone, because they were living alone and "not used to sleeping in a room with other people", which could be distressing or they had "to learn to be a patient" if they had never been hospitalized or ill before.

\section{Pros and cons for being in a single bedroom versus a four bedroom}

The interviews showed that there were both pros and cons for being hospitalized in a single bedroom and a four bedroom. The pros for being hospitalized in a single bedroom were that you "were not disturbing others if you felt bad" and "you should not show consideration for others". Another issue was that you did not need to "respond to others situation" as this could be hard in a situation where you were ill and vulnerable and "you could talk to others (health professionals or relatives) without anybody listening to your conversation". If you had nausea or/and a gastric tube it was good not to "smell the food of others" which could worsen the nausea. However, being in a single bedroom could mean loneliness in a difficult situation, because you only had few contacts during the day and night. "It was very boring, but of course it depends on how you feel" and "you do not get social relations with others in the same situation" and "very few relatives to other patients or health professionals came to your room". This could mean that you were alone with your thoughts most of the day and night, which could stimulate your imagination in a negative direction.

To be hospitalized in a four-bedroom seemed to be "therapeutic" because of being together with other patients in the same situation. There is a "community" that is very special and "affect your mood" in a positive way, because "you were distracted from your negative thoughts and concerns". However, being with others could also be negative if there was much noise and disturbancies during the night, which affected your mood during the day due to tiredness. A positive aspect of being hospitalized in a four bedroom was that you get "information related to your illness and treatment from others and can benefit from this". This information could come from other patients, but also from health professionals that were talking to other patients in the room. In a four bedroom "you keep an eye on the others to make sure that they are allright" and "support each other", which seemed to generate comfort and safety. On the other hand, it could be very hard to capture the stories of others in the room, when you were filled with your own thoughts and concerns.

\section{Discussion}

Most patients in our study preferred single bedrooms before admission, but many changed their mind after admission. The company of fellow patients seems to be of great importance for patients undergoing fast track surgery for rectal cancer. The patients seem to find the company healing. In addition, being with fellow patients contributed to feeling safer. However, they experienced problems with disturbances like sound and too much activity in a four bedroom, especially at night. Most patients preferred single bedrooms 
when talking to visitors and when they felt very sick. Despite of this, many patients preferred four bedrooms over single bedrooms because of the company from fellow patients. According to Larsen et al. patients have an ambiguous view of fellow patients. On one hand, being hospitalized in a multi bedroom with other patients causes lack of privacy but on the other hand this accommodation offers support, comfort and company. Despite of the challenges, 18 of 20 patients preferred to be in a multi bedroom with other fellows unless they were too ill to interact [18].

This is contrary to the results of Ehrlander et al. who reported that $79 \%$ of patients in their survey study preferred single room because of their wish for privacy. The arguments for those preferring a multi bedroom were exchange of conversation and assistance between fellows, which is in accordance with the findings in the present study [19]. At the same time, it was difficult not to let oneself be involved in the fellow patients, which could be too much, when you were in such a vulnerable situation.

Persson et al. found that the patients' culture of taking care of each other and enjoying each other's company contributed to a feeling of safety and time passing more quickly, however this is vulnerable if fellow patients become very sick or delirious [11]. This supports our finding of patients preferring single bedrooms when feeling very sick. Studies of patients in a hospice and patients with advanced cancer also show that patients seek the company of fellow patients in multi bedrooms but when death is near single rooms are preferable according to both patients and staff $[12,20]$.

A theme in our study was the feeling of isolation in single bedrooms. Risk of patients isolating in single rooms and not getting out of bed is a step back seen in the context of fast track surgery progress where early mobilization is a main reason for shorter hospital stay. When patients have all they need in their room they are not naturally encouraged to get out of bed [16]. This theory is supported by Williams et al. who found that patient in single-rooms were more likely to use the bell more often because they felt isolated and not safe going out of bed alone [21].

A preference of being admitted to a single bedroom was that you could talk to your visitors or the health care professionals without having the conversation overheard by others. However, at discharge the patients expressed that an advantage of being in a multi bedroom was the amount of information about their own disease they had had, when health care professionals informed fellow patients - information they otherwise might not have had. This is in accordance to the study by Larsen et al. [18], who found that this issue was experienced positively. However, some patients also regarded this enforced listening as distressing [18].

\section{Conclusion}

Before admission, the patients often preferred single bedrooms contrary to multi bedrooms. In many cases, this preference changed due to the advantages of being admitted with fellow patients, which were described as a healing factor. This contributed to their safety as they were keeping an eye on each other. Though, disturbances and lack of privacy were challenging.

\section{Perspectives}

Our results are quite interesting in relations to health care politics. Single bedrooms seem to be the tendency in modern hospital design in
Europe and North America. There is no doubt about the increased comfort new modern buildings will bring to patients, relatives and staff. But is all single bedrooms the best solution? The potential joy, education and comfort a fellow patient might provide is in danger of extinction, if we do not re-think the ward design in relation to community building.

\section{Ethical Considerations}

This study did not need consent from The National Committee on Health Research Ethics in Denmark but was registered at The Danish Data Protection Agency under Health Science Research of the North Denmark Region (2008-58-0028), id-no. 2016-140. Participation was voluntary and the participants signed an informed consent form after receiving information about the study orally and in writing. Anonymity and confidentiality were ensured by safekeeping and anonymizing data.

\section{Fundings}

There is no funding to report for this study.

\section{Conflict of Interest}

There are no conflict of interest for any of the authors.

\section{References}

1. Danish Regions (2017) Key themes of the hospital construction project.

2. Dowdeswell HB, Erskine J (2004) Hospital ward xonfiguration determinants influencing single room provision. NHS Estates Engl Eur Heal Prop Netw.

3. Van de Glind I, De Roode S, Goossensen A (2007) Do patients in hospitals benefit from single rooms? A literature review. Health Policy 84: 153-161.

4. Ulrich RS (1984) View through a window may influence recovery from surgery. Science 224: 420-421.

5. Laursen J, Danielsen A, Rosenberg J (2014) Effects of environmental design on patient outcome: A systematic review. HERD 7: 108-119.

6. Walch JM, Rabin BS, Day R, Williams JN, Choi K, et al. (2005) The effect of sunlight on postoperative analgesic medication use: A prospective study of patients undergoing spinal surgery. Psychosom Med 67: 156-163.

7. Ulrich RS, Zimring C, Zhu X, DuBose J, Seo HB, et al. (2008) A review of the research literature on evidence-based healthcare design. HERD 1: 61-125.

8. Chaudhury H, Mahmood A, Valente M (2005) Advantages and disadvantages of single-versus multiple-occupancy rooms in acute care environments: A review and analysis of the literature. Environ Behav 37: 760-786.

9. Lorenz SG (2007) The potential of the patient room to promote healing and well-being in patients and nurses: An integrative review of the research. Holist Nurs Pract 21: 263-277.

10. Maben J, Griffiths P, Penfold C, Simon M, Anderson JE, et al. (2016) One size fits all? Mixed methods evaluation of the impact of $100 \%$ single-room accommodation on staff and patient experience, safety and costs. BMJ Qual Saf 25: 241-256.

11. Persson E, Maatta S (2012) To provide care and be cared for in a multiplebed hospital room. Scand J Caring Sci 26: 663-670.

12. Williams C, Gardiner C (2015) Preference for a single or shared room in a UK inpatient hospice: Patient, family and staff perspectives. BMJ Support Palliat Care 5: 169-174.

13. Chaudhury H, Mahmood A, Valente M (2006) Nurses' perception of single-occupancy versus multioccupancy rooms in acute care 
Citation: Brauner AB, Jørgensen L, Madsen SB, Bernstein I, Petersen HK (2017) Experiences of Being Hospitalized in a Single Bedroom versus a Four Bedroom: An Interview Study. Adv Practice Nurs 2: 141. doi:10.4172/2573-0347.1000141

Page 4 of 4

environments: An exploratory comparative assessment. Appl Nurs Res 19: 118-125.

14. Kulik JA, Mahler HI (1987) Effects of preoperative roommate assignment on preoperative anxiety and recovery from coronary-bypass surgery. Health Psychol 6: 525-543.

15. Larsen LS, Larsen BH, Birkelund R (2013) An ambiguous relationship - a qualitative meta-synthesis of hospitalized somatic patients' experience of interaction with fellow patients.", Scand J Caring Sci 27: 495-505.

16. Persson E, Anderberg P, Ekwall AK (2015) A room of one's own--Being cared for in a hospital with a singlebedroom design. Scand J Caring Sci 29: 340-346.

17. Kvale $\mathrm{S}$, Brinkmann S (2009) Interview - introduktion til et håndværk 2 edition. Copenhagen: Hans Reitzels Forlag.
18. Larsen LS, Larsen BH, Birkelund R (2014) A companionship between strangers - the hospital environment as a challenge in patient-patient interaction in oncology wards. J Adv Nurs 70: 395-404.

19. Ehrlander W, Ali F, Chretien KC (2009) Multioccupancy hospital rooms: Veterans' experiences and preferences J Hosp Med 4: 22-27.

20. Rowlands J, Noble S (2008) How does the environment impact on the quality of life of advanced cancer patients? A qualitative study with implications for ward design. Palliat Med 22: 768-774.

21. Williams AM, Irurita VF (2005) Enhancing the therapeutic potential of hospital environments by increasing the personal control and emotional comfort of hospitalized patients." Appl Nurs Res 18: 22-28. 